\title{
DEMOCRACIA E GOVERNOS AUTÔNOMOS - UMA REFLEXÃO A PARTIR DA EXPERIÊNCIA DO EXÉRCITO ZAPATISTA DE LIBERTAÇÃO NACIONAL ${ }^{* 1}$
}

\author{
Alexander Maximilian Hilsenbeck Filho \\ Mestrando em Ciências Sociais (Unesp-FFC), \\ Marília, Universidade Estadual Paulista \\ E-mail: a.hilsenbeck@gmail.com
}

\begin{abstract}
Resumo
É notório o peso das lutas dos movimentos indígenas na América Latina, transformando-os em sujeitos políticos de natureza coletiva com reivindicações próprias, que tem como cerne a modificação do Estado e da democracia representativa. A luta por livre-determinação das comunidades indígenas deita novas questões para o pensamento político. Através da análise das comunidades mexicanas do Exército Zapatista de Libertação Nacional percebemos as contribuições e problemáticas que o exercício de governos autônomos podem trazer para o quadro da A.L. de uma forma mais ampla, confrontando-os com o modelo de democracia ocidental, baseado em um Estado com tendências homogeneizadoras. Apenas a ratificação de convênios internacionais, não é suficiente para a concretização do respeito a plurinacionalidade do Estado, para tanto, se faz necessário que estes movimentos consigam transcender sua especificidade étnica e atuem em conjunto com outros movimentos na luta por uma democracia mais participativa.

Palavras-Chave: Democracia. Exército Zapatista. América Latina.
\end{abstract}

\begin{abstract}
It is notorious how the fights promoted by indigenous movements in Latin America turn those people in naturally collective and political individuals who have their own demands and who have as their innermost intention the modification of the State and of the representative democracy. The fight for free-determination of those indigenous communities poses new issues for the political thought. Through the analysis of the Mexican Zapata's army for National Freedom, we can have a wider view of the contributions and problems autonomous governments bring to the scenario of Latin America, confronting them to the western model of a democratic State with homogenized tendencies. Only the acceptance of international agreements is not enough for the effectuation of respect to pluri-nationality of the state. It is also needed that these movements be able to transcend their ethnical specificity and promote a joint action with other movements in the fight for a more participative democracy.
\end{abstract}

Key-Words: Democracy. Zapatista Front. Latin America. 


\section{A Conjuntura Latino-Americana}

É cada vez mais notório o peso que tem adquirido as lutas dos movimentos indígenas na América Latina, transformando-os em sujeitos políticos com reivindicações próprias, que não obstante, colocam como cerne (em última instância) a modificação - ou pelo menos a ampliação e reformulação - do Estado Nação e suas formas tradicionais de política, desta forma transcendendo a própria especificidade étnica destes movimentos. Conforme Pablo Dávalos,

La incursión de los movimientos indígenas como movimientos sociales, y la constitución de los movimientos indígenas como sujetos políticos, representan uno de los fenómenos sociales y políticos más novedosos y complejos en la historia reciente de América Latina (DÁVALOS, 2005).

Neste quesito, a luta por livre-determinação e conseqüentemente autonomia e autogoverno das comunidades indígenas, colocam novas questões para o pensamento político. $O$ exercício desses direitos fundamentais é condição essencial para que os pueblos indígenas possam desenvolver suas capacidades para intervir nos assuntos básicos de sua comunidade conforme sua cultura, esta entendida "en el mas amplio sentido [...] comprende[ndo] formas de organización social, económica y política propias, formas de administración de justicia, de valores, cosmovisión, relación con la naturaleza diferentes” (GÓMEZ, 2005).

Os pueblos indígenas se colocam, assim, como sujeitos de direito de natureza coletiva e, portanto, a comunidade como entidade histórica e de direito público, indo contra o princípio de generalidade da lei, de um conceito de cidadania homogêneo, uniforme e com pretensões "nacionais", de homogeneidade cultural; a autonomia e o autogoverno se fazem para garantir as próprias formas de organização e cultura de povos indígenas mas, no caso específico da América Latina. atrelados ao Estado nacional. Trata-se de buscar o respeito à diversidade, a uma forma de organização política e cultural que não se quer assimilada completamente a uma organização ocidental que os têm negado, marginalizado e discriminado; um respeito a pluriculturalidade do Estado-Nação, que apesar de sua pretensão homogeneizadora, contém em suas entranhas diversas formas de organização, de diversidades culturais que se colocam para além de uma simples questão "folclórica" de vestimentas

\footnotetext{
${ }^{1}$ Uma versão resumida deste trabalho foi apresentada no XII Fórum Estudantil Latino Americano de Antropologia e Arqueologia, realizado na cidade de Popayán, Colômbia, 2005 e também na XII Jornada de Jovens Pesquisadores da AUGM, realizada na cidade de Tucumán, Argentina, 2005.
} 
e certos costumes "triviais"2.

Com o desenvolvimento capitalista, a consolidação do Estado burguês, e sua ideologia liberal, se procurou tornar hegemônica a cultura do ocidente europeu,, relegando às outras formas culturais o "título" de mortas ou arcaicas; buscou-se assim ocultar o "problema cultural", graças à própria pretensão normativa do paradigma liberal que pretende se colocar como civilizatório e mesmo ontológico como um dever ser da história. Com a formação dos Estados-nação independentes latino-americanos procurou-se escamotear a questão das diferenças culturais ao se adotar o capitalismo - e sua filosofia liberal como modelo de organização societal, transformando todos os seus habitantes em "cidadãos livres" diante do mito da Nação. Mesmo as idéias de progresso e modernidade "racional", foram utilizadas como vetores de um "esquecimento" ou abandono das tradições culturais e materiais dos indígenas. Dessa forma é levado ainda a cabo um processo de esquecimento coletivo promovido pelas atuais democracias neoliberais, que procuram reconstruir a história a seu bel prazer, como uma maneira eficiente de dominação.

Contudo, a maior parte destes Estados se tornou excludente e homogeneizador, por não corresponder a uma realidade social complexa e heterogênea, por reconhecer uma só identidade e nacionalidade - e assim tentar esconder uma radical fragmentação e divisão sociocultural e econômica -, acarretando a luta dos povos indígenas, luta essa que no campo político se apresenta como crítica direta à democracia do modelo representativo burguês e ao Estado excludente e hierárquico. Desta forma, a busca para a "solução" do "problema étnico" se traduz em um complexo desafio sóciopolítico que

[...] ha radicado en el rechazo a la diferenciación cultural y lingüística, propio de un proyecto político centralista y exclusionista que reconece la cultura e ideología de la clase dominante y ve al otro como inferior, no civilizado, rezago del atraso y subdesarrollo que hay que superar, y como obstáculo para la unidad nacional (SIMBAÑA, 2005.)

Nos marcos atuais de autogoverno e autonomia indígena, uma das experiências mais notórias é a levada a cabo pelo Exército Zapatista de Libertação

\footnotetext{
2 Desde essa perspectiva, se pode vislumbrar a importância do Convênio 169 da Organização Internacional do Trabalho (OIT) sobre Povos Indígenas e Tribais, em que se assumem conceitos básicos relativos ao âmbito do direito coletivo, impondo efeitos jurídicos imediatos à ordem interna de quase todo o sistema constitucional latino americano, não obstante esse convênio ser motivo de resistências (mesmo nos países que o ratificaram), em decorrência de sua utilização como forma de luta pelos povos indígenas e dele ser manipulado e deturpado em partes pelos governos, além de suas limitações, como seu caráter generalizante e o atrelamento - e as limitações dos mecanismos de controle - da OIT aos Estados nação (Gómez, 2002).
} 
Nacional e pelas comunidades indígenas do sudeste do México ${ }^{3}$, ainda que, cabe salientar, essa não seja a única ${ }^{4}$.

Segundo Luís Hernández Navarro, é demanda antiga e insatisfeita de povos de várias regiões de Chiapas a remunicipalização ou autonomia, isto em decorrência de diversos fatores, tais como:

A distância geográfica e a falta de comunicação de centenas de comunidades com as suas cabeceiras municipais [cidade ou povoado em que se encontra a prefeitura de um município] oficialmente reconhecidos, o fato de que as autoridades sejam com freqüência parte ou representantes dos grupos de poder, o manejo discricionário dos recursos e sua distribuição sem equidade, a falta de correspondência entre os limites territoriais dos municípios e o hábitat de seus povoadores têm alimentado durante décadas as aspirações remunicipalizadoras (ARRELANO; OLIVEIRA, 2002, p. 169-170).

Tais aspirações o EZLN está tornando possível, à margem da legalidade institucional ${ }^{5}$, contando com o apoio, reconhecimento e participação não apenas de comunidades zapatistas, mas também de muitas outras agrupadas em várias organizações - inclusive contrárias a via armada.

A possibilidade de autonomia indigena acaba por significar um Estado plural que se pretende mover por outros marcos que não o Estado homogeneizador liberal, colocando novas diretrizes jurídicas e políticas ${ }^{6}$. Essa

\footnotetext{
${ }^{3}$ O EZLN veio a público em $1^{\circ}$ de janeiro de 1994, ao deflagrar uma guerra ao Governo Federal, não obstante se utilizar de uma tática de guerrilha este movimento indigena se constitui mais como um antípoda das guerrilhas que a América Latina conheceu, ao não colocar como paradigma a conquista do poder estatal e realizar uma "guerra midiática" com o governo, além de impulsionar formas democráticas de participação da "sociedade civil", entre outros anti-modelos das guerrilhas tradicionais. (GENNARI, 2001; HILSENBECK FILHO, 2004a, 2004b).

${ }^{4}$ Há uma longa tradição indigena na região de Chiapas no processo de construção de autonomia, contudo, utilizaremos como marco das autonomias zapatistas dezembro de 1994, época em que, em decorrência de uma tentativa infrutífera de diálogo com o governo federal e municipal (ambos do Partido Revolucionário Institucional, forma de Partido-Estado que governou o México por mais de 70 anos), o EZLN declara terminada a trégua - firmada de forma unilateral pelo governo após 12 dias de confronto -, e com o apoio e proteção do EZLN, em suas zonas de influência os moradores de cada região declararam a existência de 30 novos municípios na região de Chiapas, reunindo centenas de milhares de pessoas (ORNELAS, 2004).

${ }^{5}$ Tradicionalmente, há séculos, os pueblos indígenas têm violado a legalidade das instituições do Estado ocidental para defender a legitimidade de se organizarem conforme sua cultura. O EZLN está construindo essa demanda insatisfeita por vias não legais, portanto, elas continuam sendo demandas insatisfeitas, pois os municípios remunicipalizados o são enquanto municípios rebeldes, em uma autonomia que não é reconhecida legalmente pelo Estado mexicano, em sua Constituição, mas é "aceita" em sua ilegalidade jurídica pelos poderes oficiais, seja pelo próprio descaso e incompetência desses poderes oficiais, seja pelo fato de o EZLN estar armado nessas regiões e contar com amplos setores das comunidades, mesmo as não zapatistas.

${ }^{6}$ Como os pueblos indígenas colocados como sujeitos coletivos, neste aspecto enfatizando como necessário uma jurisdição pluricultural, isto porque os próprios direitos reivindicados pelos pueblos indígenas se inscrevem no direito e titularidade coletiva e não individual como no direito convencional, ao contrário de outras políticas e reivindicações de identidade, como as de gênero, sexual etc. (GÓMEZ, 2005, 2002).
} 
reivindicação,, em certo sentido, remonta a Villa e Zapata, pois a liberdade municipal foi uma das demandas da Revolução Mexicana de 1910. Conforme Navarro, sob o ponto de vista do EZLN:

[...] a autonomia como exercício da livre determinação dos povos indígenas implica a criação de um espaço no qual estes governem a si mesmos, sem a necessidade de criar um outro Estado. A autonomia implica a criação de um poder que o Estado nacional é obrigado a reconhecer. A autonomia inclui também direitos sobre o território que implicam regiões específicas (ARRELANO; OLIVEIRA, 2002, p. 281).

Ao contrário dos movimentos indígenas da década de 1970, que pleiteavam uma certa separação do Estado nacional, fica clara a aspiração dos novos movimentos indígenas na América Latina em pretender se integrar ao Estado, mas mantendo sua especificidade étnica. Assim, apesar de sua composição social - majoritariamente indígena -, o levante zapatista está longe de ser um movimento social simplesmente étnico, que busca a instauração de uma sociedade puramente indígena e uma separação do Estado mexicano; muito pelo contrário, procuram se integrar a um país que o tem sistematicamente excluído, mas permanecendo com sua especificidade - cultural e política - indígena ${ }^{7}$. Conforme um comunicado zapatista:

Por isso queremos a autonomia indígena. Não para nos separar do país e acrescentar outra nação pobre às que existem em abundância. Não para voltar a um passado do qual sequer pudemos sair [...] Para que as mulheres indígenas não mudem sua condição de marginalizadas pelo fato de ser indígenas e ser mulheres, $\mathrm{e}$ sim a mudem pela condição de ser mulheres sem importar se são ou não indígenas. Para que deixe de ser crime ser indígena, viver como indígena, pensar como indígena, ter a cor do indígena. Para que a medida do êxito político ou econômico deixe de ser esmagar aquele que é diferente e obrigá-lo a deixar de ser o que é. Não para que todos sejam como nós. Mas para sermos nós, respeitando e sendo respeitados pelo outro que é diferente de nós (BRIGE; DI FELICE, 2002, p. 76).

\section{Democracia e Autonomia em Chiapas}

O EZLN não pretende conquistar a tomada do poder estatal, mas, segundo eles, fundar uma sociedade em que a comunidade como um todo tenha a responsabilidade, o direito, os mecanismos e as oportunidades para se autogovernar, ou seja, passar a ser protagonista da mudança social e não apenas espectadores, em que seja desfeita a distinção entre governantes e governados, através do que eles chamam de uma representação em que os que mandam, devem "mandar obedecendo". Conforme um comunicado do

${ }^{7}$ É notório que a livre-determinação indígena se faz nos marcos internos do Estado-Nação, sobre isso o próprio Convênio 169 da OIT faz menção clara. 
CCRI-CG ${ }^{8}$ : "Assim nasceu nossa força na montanha: aquele que manda obedece se é verdadeiro, aquele que obedece manda pelo coração comum dos homens e mulheres verdadeiros. Outra palavra veio de longe para que este governo se nomeasse e essa palavra chamou 'democracia' este caminho nosso [...]” (Comunicado do CCRI-CG apud CECEÑA, 2001, p. 192).

Não parece que o zapatismo pretenda "subavaliar" o conceito de democracia, isto é, utilizar um conceito de democracia em que se escondam as classes e a exploração de classe, tornando invisível o capitalismo. Eles almejam uma sociedade em que impere uma democracia popular e participativa, ao contrário da democracia nos moldes da sociedade burguesa, que é apenas para uma minoria, ou melhor, em que as minorias prevalecem sobre, e subjugam sistematicamente as maiorias, esvaindo os seus conteúdos emancipadores, em decorrência de uma abstração fetichizada de um simples ato de administração. Os comunicados do EZLN, a todo o momento, denunciam os limites de uma democracia formal ou representativa, tal qual está colocada atualmente. Percebemos no zapatismo a intenção de maximizar a democracia, através da incorporação de todos os excluídos da sociedade, de uma outra forma de fazer política, em que a própria sociedade seja o real protagonista e o "poder" emane de baixo e não de cima, o que significa estender o conceito de democracia a um grau tal inadmissível por qualquer estrutura capitalista.

No sistema de democracia pensado pelos zapatistas - expresso em suas experiências de municípios autônomos -, busca-se assegurar uma representatividade real e um sistema de controle dos representantes pelos eleitores, sendo um dos princípios básicos dessa forma de representatividade a revogabilidade dos representantes, quando eles não estiverem mais cumprindo o seu mandato de acordo com as aspirações e delegações das comunidades. Assim,

[...] as autoridades de diversos povoados elegem o representante regional, depois várias regiões elegem o de área, depois o de etnia e os representantes de etnia vão nomear quem deve ir ao comitê.

A autoridade zapatista pode ser criticada junto aos seus superiores: se a comunidade não estiver satisfeita com o seu responsável local, ela o denuncia junto ao responsável regional. É aberto um inquérito, o destituem, fazem uma assembléia e nomeiam outro. $\mathrm{O}$ mesmo acontece quando são os representantes locais a terem problemas com a autoridade regional, e assim por diante até a cúpula. (MARCOS apud GENNARI, 2001, p. 22).

\footnotetext{
${ }^{8}$ Comitê Clandestino Revolucionário Indígena - Comando Geral do EZLN, a instância máxima do EZLN.
} 
Além disso, segundo Luís Hernandez Navarro,

A rebelião chiapaneca não se limita aos setores que tomaram as armas em torno do EZLN ou das comunidades que se encontram em resistência civil, mas abarca amplas camadas de comunidades com outras referências políticas. Expressa-se em regiões inteiras que não pagam o serviço elétrico ou dão uma cota ao comitê, não cobrem tampouco o imposto predial e quase não retornam os créditos do Solidariedade Pronasol (apud ARELLANO; OLIVEIRA, 2002, p. 127).

Constituem, assim, uma estratégia de poder alternativo, com uma vocação contra-institucional, enquadrada em um sistema de autonomia que abrange diversas regiões do Estado, e que contam com autoridades eleitas pelas próprias comunidades, ainda que essas não sejam, estritamente, reconhecidas pelo poder oficial. Ainda segundo Navarro, nestas regiões o governo estatal se encontra sustentado pela presença da Federação e da força pública, mas impossibilitado de governar, enquanto o governo rebelde tenta construir uma nova ordem, um regime de autonomia local.

É certo que, como aponta Boron (2003, p. 226), existe um inevitável paralelo entre as experiências de autogoverno das comunidades autônomas zapatistas e a Comuna de Paris - obviamente preservadas diversas diferenças, como o próprio âmbito de desenvolvimento do capitalismo, sua etapa histórica, a composição social dos insurgentes etc. -, contudo: "O principal é que, em ambos os casos, estamos na presença de um caso excepcional de autonomia e autogoverno das classes e grupos explorados e oprimidos, o que lhes atribui uma merecida relevância histórico-universal”.

A relação do EZLN com as comunidades indígenas, ou as "bases de apoio", é um ponto que nos parece crucial, pois em certa medida, é um dos elementos que distinguem o zapatismo dos outros movimentos de libertação nacional da América Latina e Central, e que não permite que ele seja cooptado pelo establishment e sua forma de política, o que prejudicaria as reivindicações e resoluções das necessidades da comunidade.

Assim, acreditamos que um dos elementos constitutivos e que garantiu o sucesso da rebelião zapatista foi a forte estrutura da comunidade local, isto é, as estreitas relações pessoais, o forte vínculo interno que serviu como um facilitador organizativo. Como nos mostra James Petras e Steve Vieux: "o movimento se construiu mediante a educação política e a ação direta [...] embora se empreendia a organização a longo prazo do movimento da guerrilha, era comum a ocupação das terras com o fim de abastecer aos camponeses" (PETRAS; VIEUX, 1998, p. 59). Estas atitudes de ação direta e vínculo com as necessidades dos camponeses indígenas foram fatores marcantes e determinantes na guerrilha chiapaneca, pois procurou-se resolver também os 
problemas imediatos das comunidades; disto surgiram os Aguascalientes e os Caracóis, atendendo as necessidades das comunidades - como saúde, educação etc. - através da auto-organização, construindo o que eles denominam uma ponte para um "novo mundo". Ao mesmo tempo em que se caminha para este objetivo, não se espera chegar primeiro a este "novo mundo" para depois disto modificar as relações e organizações sociais; estas se dão concomitantemente, em um processo dialético de construção, manifesto, por exemplo, em mudanças nas relações de gênero e na tomada de decisões comunitárias.

Logo, a transformação do mundo, na concepção do zapatismo, seria uma tarefa diária - e não uma meta final -, não se devendo esperar as condições objetivas para se realizar a revolução e a partir daí, gerar uma subjetividade correspondente, uma forma diferente de nos relacionarmos e nos organizarmos; essa seria uma tarefa cotidiana, com o fim de se construir uma nova sociedade.

Como afirmou Ana Esther Ceceña no II Fórum Social Mundial em Porto Alegre, "Os princípios zapatistas consideram que a revolução é o caminho - e não o ponto de chegada - para se construir um mundo novo, e temos que começar a partir de hoje”. (CECEÑA, 2001). Porém neste novo caminho, a ser trilhado para a mudança social, para a revolução, o movimento zapatista não coloca certezas, a não ser que é o próprio caminhar que se constitui em revolução. Para os zapatistas,

[...] a criação de uma sociedade baseada na dignidade pode ser conseguida somente por meio do desenvolvimento de práticas sociais baseadas no reconhecimento mútuo dessa dignidade [...] Aqui não pode ser questão de 'primeiro a revolução, depois a dignidade: a própria dignidade é o movimento da revolução. (HOLLOWAY, 2002, p. 7).

É verdade, contudo, que estas relações e modificações dentro das comunidades não se dão de uma forma harmônica e idealizada ${ }^{9}$, tal qual encontramos em certos autores. Após o levante, as condições de algumas comunidades melhoraram, porém, em outras se teve um endurecimento maior de suas situações de vida, pois houve, em certa medida, um aumento da

\footnotetext{
${ }^{9}$ Quanto a este fato, o próprio Subcomandante Marcos afirma no comunicado Chiapas: a décima terceira estela.Quinta parte: uma história,: "Contudo, não quero que fique a impressão de que se trata de algo perfeito e que seja idealizado. O "mandar obedecendo" nos territórios zapatistas é uma tendência, e não está isenta de sobe-e-desce, contradições de desvios, mas é uma tendência dominante. Que isso tem resultado em benefício das comunidades fala o fato de ter conseguido sobreviver em condições de perseguição, hostilidade e pobreza que poucas vezes podem ser encontradas na história do mundo. Não só, os conselhos autônomos têm conseguido levar adiante, com o apoio fundamental das "sociedades civis", um trabalho titânico: construir as condições materiais para a resistência" (Disponível no site Ya Basta! da FZLN).
} 
pobreza e da fome, em decorrência do cerco militar do exército federal.

Como afirma Crespo (1996, p. 41), "Muitos camponeses não puderam sair para o campo e semear o milho e o feijão que representam a sua dieta básica, pois temiam que os soldados atacassem suas casas e suas mulheres [como em muitos lugares sucedeu]".

Figueiredo (2003), em sua pesquisa de campo, publicizada em sua dissertação de mestrado, explicita alguns dos conflitos existentes nestas comunidades autônomas, pois nem todas contam com maioria zapatista. Afirma que alguns habitantes não vêem mesmo nenhuma diferença entre o governo do PRI e os municípios controlados pelos zapatistas, que são extremamente dependentes da ajuda oriunda da sociedade civil, através de projetos, ações voluntárias e doações. Há projetos que se concentram em comunidades autônomas de grande visibilidade, enquanto outras comunidades não recebem nenhum tipo de auxílio -, além do que, muitas das organizações dos movimentos camponeses que surgiram na década de 1970 estavam tratando projetos com o governo e viram suas portas serem fechadas pelo envolvimento com os zapatistas, afinal, o governo só destina verbas para comunidades que não tenham ligação com o EZLN.

Um outro fator importante e distintivo do EZLN em relação a outras formas de guerrilhas e experiências autônomas é que se por um dado momento imperou em muitas comunidades uma administração militar, voltada para o confronto com o exército, e que gerava certos conflitos dentro das sociedades, o zapatismo tentou atenuar, ou superar esta situação com a construção dos Caracóis - no lugar dos extintos Aguascalientes -, neles, o EZLN se retirou enquanto exército beligerante, limitando-se ao confronto com o exército e grupo paramilitares, enquanto a administração e auto-organização era exercida pelas próprias comunidades, pois a presença do EZLN poderia de alguma forma constranger ou influenciar negativamente na construção desta autonomia e autodeterminação das comunidades ${ }^{10}$.

\footnotetext{
${ }^{10}$ A substituição dos "municípios autônomos" e os "aguascalientes" para os "caracóis" e as "juntas de bom governo" se deu para buscar superar os problemas que surgiram no próprio processo de construção da autonomia. Assim, enquanto os "municípios autônomos" reuniam comunidades e micro-regiões, as (cinco) "juntas de bom governo" reúnem regiões mais extensas, e logo buscam potencializar os alcances da autonomia; os "caracóis" são as sedes das "juntas de bom governo", é interessante ressaltar que estas estão integradas por um ou dois membros dos "conselhos autônomos", denotando-se uma preocupação em manter o vínculo direto com as comunidades. Um outro elemento presente na tentativa de se chegar a "uma fase superior de organização" autônoma são as medidas para evitar a concentração do apoio externo apenas nas comunidades de acesso mais fácil; e também extremamente importante, com a criação das "juntas de bom governo" e os "caracóis" é o fato do EZLN se afastar das funções de governo, de buscar uma independência às tarefas do governo, pois a estrutura do exército (hierarquias, medidas de segurança etc.), criaram situações não democráticas e rígidas que levaram a um retrocesso na criação de novas sociabilidades e construção da autonomia, "contaminando" as comunidades (ORNELAS, 2004).
} 
Além do mais, contrariamente ao que encontramos em certos autores, não podemos cair em uma idealização e simplificação do conceito de democracia colocado pelos zapatistas, pois ele se apresenta muitas vezes ambíguo e discutível. Conforme assinala Yvon Le Bot "o modo de governo habitual [das comunidades indígenas tradicionais mexicanas] é uma gerontocracia masculina: um sistema de autoridade (o sistema de cargos) hierárquico e vertical, dominado pelos principales e os xamãs, e manipulado por caciques que asseguram a sua inserção no sistema político nacional” (LE BOT, 1997, p. 56). A democracia do consenso, através das assembléias, não exclui a violência simbólica, e mesmo a física; a coação sobre o indivíduo; a predominância de algumas personalidades e pequenos grupos, a "democracia da maioria" sem o respeito pelas minorias etc., assim "[...] a prática do consenso nas novas comunidades pode demonstrar-se tão asfixiante como o modelo autoritário tradicional" (LE BOT, 1997, p. 57).

É certo que como salienta Le Bot, as comunidades zapatistas (por mais que idealizem os costumes e tradições e mesmo mantenham uma certa indefinição e ambigüidade a esse respeito) são oriundas de setores indígenas que construíram novas comunidades, que romperam, em certo sentido, com estas comunidades tradicionais, e se uniram fortemente em uma vontade coletiva, em que se fazia primordial a participação da maioria, a igualdade e a autonomia, mesmo que por vezes, ou em determinados períodos, tivesse ocorrido uma intolerância em relação às opiniões individuais ou minoritárias, justificado por imperativos de sobrevivência nos anos iniciais de êxodo e implantação, pela necessidade de resistir às agressões do Estado, dos latifundiários, grupos paramilitares etc..

Analisando estas experiências em sua trajetória histórica, percebemos que, como afirmou o Subcomandante Marcos, "[...] a democratização das comunidades passa pela sua abertura à sociedade global e pelo confronto com outras modalidades de consulta e de tomada de decisão diferentes das que lhe são habituais" (MARCOS apud LE BOT, 1997, p. 57). A experiência das comunidades autônomas zapatistas tem demonstrado essa abertura para a democratização e exercício de um autogoverno não autoritário. Neste quesito, essas experiências contribuem para a formação de uma nova forma de democracia, uma mescla entre as formas de organização tradicionais indígenas, a democracia representativa e direta. Não como um modelo teórico pronto e acabado a ser copiado, mas como experiências efetivas e reais de autonomia e experiências coletivas de resistência, possibilidades em construção que devem ser analisadas, criticadas e apoiadas, a fim de se preservar seus aspectos positivos e superar os negativos, mostrando que não é um "fim da história”, mas a possibilidade de um novo começo que 
está sendo construído ${ }^{11}$.

Trata-se [...] de inventar uma democracia plural, enriquecida por conceitos e práticas políticas que não são reconhecidas no actual sistema político. O que exige por exemplo conciliar democracia e comunidade, combinar democracia directa e eleição de representantes, participação e representação, um problema cuja importância não se limita a Chiapas, nem ao México, uma questão cuja actualidade e projecção universal se manifestam nas fortes contestações da democracia ocidental que acontecem no mundo inteiro (LE BOT, 1997, p. 64)

Os integrantes do zapatismo e suas comunidades estão aprendendo a realizar e (re)inventar a democracia. O Subcomandante Marcos não apregoa que a democracia comunitária (tal qual exercida nos municípios autônomos), do consenso, seja expansível para qualquer nível:

Acho que essa forma de democracia só é possível na vida comunitária. Funciona nas comunidades índias porque a sua organização social o permite, mas não se pode generalizá-la, não se pode transferir este modelo para outros cenários, para as cidades, ao nível do estado ou do país, por exemplo. O que importa reter, na nossa opinião, é o controle do colectivo sobre a autoridade [...] mas é necessário encontrar mecanismos que permitam à sociedade em geral controlar os governos e sancioná-los, decidir se devem permanecer em funções ou não e, eventualmente castigá-los. Deveria ser a sociedade a controlar o governo e não o governo a controlar a sociedade [...] (MARCOS apud LE BOT, 1997, p. 161).

A democracia direta tem suas vantagens e seus limites ${ }^{12}$. Com o EZLN há ocorrido uma abertura, um alargamento no horizonte político das comunidades indígenas, quando novos elementos são adicionados de uma forma dialética, tanto para as comunidades indígenas tradicionais quanto para a experiência ocidental.

Boron (2003) identifica na formulação zapatista de "democracia para todos” um alarmante romantismo em relação à reação das classes e grupos retirados do poder, pois as classes dominantes do império e seus aliados travarão uma tenaz e absoluta oposição que procurará utilizar todos os recursos

\footnotetext{
${ }^{11}$ Como já ressaltamos, o movimento indígena, não só no México, mas na América Latina (como no Equador, Bolívia etc.) tem colocado em xeque a questão da democracia ocidental burguesa. Como ressaltou Pablo Davalos (2005), a proposta de plurinacionalidade do movimento indígena equatoriano pretende posicionar um novo dever-ser do Estado - tanto em sua contratualidade como em sua soberania -, da política e da própria sociedade, e nesse sentido questionam profundamente as pretensões normativas do paradigma liberal que se quer civilizatório e ontológico. Assim, o fato de os movimentos indígenas se tornarem movimentos sociais e sujeitos políticos (coletivos) denota uma nova gama de complexos fenômenos sociais e políticos a serem estudados, compreendidos e. quiçá, desenvolvidos, que contrapõem a figura do homo economicus (individualista) ocidental ao sujeito comunitário indígena, que se move por outros valores, políticos, sociais e econômicos (DÁVALOS, 2005b).
} 
possiveis, desde a sedução e persuasão até a violência mais atroz para não perder seus privilégios. Somos levados a concordar com Boron no tocante ao fato de que as classes e grupos dominantes utilizarão todas as ferramentas possíveis para manter sua posição, como tem mostrado a experiência ao longo dos tempos. Porém, também é certo que isso o sabem os zapatistas, seja pelos séculos de experiência indígena sob o jugo da espoliação e dominação, seja pelo cotidiano de morte e esquecimento que essas comunidades vivem e resistem.

De qualquer forma, o vínculo comunitário e o desenvolvimento de uma democracia direta dentro das comunidades é um elemento essencial para a resistência chiapaneca, segundo Petras e Vieux: "O nexo entre o exército guerrilheiro, as milícias comunitárias e a comunidade está baseada nos vínculos, por sua vez, familiares, comunitários e pessoais que reforçam a solidariedade política, social e de classe" (PETRAS; VIEUX, 1998, p. 62), o que acaba por limitar o êxito da política governamental em travar uma "guerra de baixa intensidade ${ }^{13}$ ", de criar conflitos e competições dentro das comunidades, para a aquisição de recursos governamentais escassos, através de corte do abastecimento alimentar por parte do exército e doações de alimentos por programas assistenciais como o Pronasol. Deste modo, o movimento zapatista, pelo seu forte vínculo com as comunidades e pela sua prática política de consulta constante a estas, coloca como questão nevrálgica as mudanças socioeconômicas, novas relações democráticas, o respeito à cultura e à autonomia indígena, e à satisfação das demandas por terra e justiça, como condição sine qua non para o desarme militar. Para Petras e Vieux:

\footnotetext{
${ }^{12}$ Há na tradição marxista vertentes que percebem a democracia mesma como uma forma limitada de liberdade, isto é, o máximo possível a que pode chegar a liberdade política (portanto, limitada, em contraposição a liberdade humana de fato). A democracia seria o ápice de uma liberdade restrita em âmbito abstrato, tratando-se então, de efetivar em âmbito concreto a complexa liberdade social, irrestrita. A dicotomia se apresentaria então, entre democracia (liberdade formal) e emancipação humana (liberdade real) (TONET, 1997), (CHASIN, 1989). Karl Marx apontava os limites de uma democracia burguesa, sempre comprimida pela exploração capitalista, sendo, portanto, uma democracia para uma minoria, fazendo com que a grande maioria ficasse alijada da maior parte do campo político e dos direitos reais, tornando-se apenas uma democracia para uma minoria insignificante. Para Lênin (1985), a idéia de que a democracia constitui um processo de ampliação da liberdade é uma ilusão, havendo a necessidade da ditadura do proletariado, com vistas a reprimir os direitos dos exploradores e de se controlar a contra-revolução. Desse modo, a ditadura do proletariado seria uma ditadura democrática, uma democracia para a grande maioria do povo, fundamentalmente diferente da democracia burguesa liberal. Para Lênin, portanto, apenas com a extinção do Estado se poderá falar de liberdade de fato, pois mesmo na ditadura do proletariado haveria a repressão e a violência, só que infligidas a uma pequena parcela da população humana, ao inverso da democracia liberal. Logo, o pensador russo crê que a concretização real da liberdade só se dará com o fim do Estado e a superação da própria democracia. Rosa Luxemburgo, por sua vez, ressalta a necessidade da ampla e irrestrita constituição da liberdade (e concretização dos direitos burgueses) para a auto-educação (e emancipação) dos trabalhadores (LUXEMBURGO, 1986; LOUREIRO, 1995).
} 
"Neste sentido, os comandantes zapatistas se distinguem basicamente dos líderes salvadorenhos, guatemaltecos [...]" (PETRAS; VIEUX, 1998).

Logo, no zapatismo, a autonomia das assembléias comunitárias se constitui como um baluarte contra o domínio vertical do próprio movimento e "neste sentido, Chiapas é, de fato, um novo tipo de política com uma nova agenda socioeconômica" (PETRAS; VIEUX, 1998, p. 63). Através desta autonomia das assembléias das comunidades, enfocada na prática política de uma democracia direta, os zapatistas estão não apenas retomando - em certa medida - mais de 500 anos de tradição, mas resistindo a certos preceitos capitalistas, pois como afirma o próprio subcomandante Marcos: "O trabalho coletivo, o pensamento democrático, a aceitação das decisões da maioria, são algo mais que uma tradição nas áreas indígenas, tem sido a única possibilidade de sobrevivência, de resistência, de dignidade e de rebeldia" (MARCOS, 1992), o que aponta, paradoxalmente, para uma nova forma de fazer política.

\section{Considerações}

Como observamos anteriormente, no zapatismo há uma clara relação entre a organização política, os movimentos sociais e as comunidades, em termos participativos. O EZLN parte da premissa de que não é o único que tem idéias e propostas, não se utilizando simplesmente de esquemas verticais préelaborados, que acabam por anular a iniciativa das "massas". Eles não se colocam como uma vanguarda, mas entendem-se como um "sintoma", como uma "força a mais", que se soma com outras forças, a fim de concretizar "A possibi-

\footnotetext{
${ }^{13}$ Atualmente, segundo os comunicados dos próprios zapatistas e de testemunhos de observadores internacionais, vive-se em Chiapas uma situação de "guerra de baixa intensidade", ou seja, o governo, ao mesmo tempo em que declara uma situação de paz, designa para o território chiapaneco praticamente um terço do efetivo militar buscando, por um lado, desgastar a imagem do EZLN, minar o apoio das comunidades ao movimento através de uma guerra psicológica, e por outro lado, fazer um cerco à guerrilha. São muitos os casos relatados pela população de invasões do exército às comunidades, com saques, destruição das plantações, prisões e estupros, sempre com a desculpa de estarem ali em decorrência de "treinamento", à procura de grupos paramilitares, plantações de drogas etc., além disso, o governo busca cooptar as comunidades com diversos programas assistenciais. "Além das barreiras da polícia e do Exército, dos interrogatórios, das prisões arbitrárias, das ameaças, das provocações e dos ataques às comunidades, os soldados têm se dedicado a abrir estradas na selva, destruir colheitas, derrubar casas, centros comunitários, postos de saúde, escolas, bibliotecas, enfim, a aniquilar todo o trabalho que o EZLN havia implantado em várias regiões do Estado. Por estes meios, o Exército procura sufocar as relações das comunidades com o mundo externo, dificultar ao máximo a vida no seu interior, debilitar e esgotar as bases de apoio zapatistas e criar uma barreira de contenção à possível expansão do EZLN" (GENNARI, 2001, p. 27). Para uma análise detalhada sobre o que vem a ser a "guerra de baixa intensidade", ver o artigo de Francisco Pineda: La guerra de baja intensidad (PINEDA, 1996). Hector Saint-Pierre irá se utilizar do conceito de "contra-insurgência" e não o de "guerra de baixa intensidade" para caracterizar a relação entre as forças militares - e paramilitares - e o EZLN na região de Chiapas. (SAINT-PIERRE, 1999).
} 
lidade de desconstrução das amplas e profundas redes de dominação que o capital logrou desenvolver [que na concepção zapatista] [...] só poderá se concretizar com o encontro de todas as rebeldias e com o concurso dos dominados de todas as partes do mundo" (CECEÑA, 2001, p. 194). Logo, em sua luta diária, no cotidiano do EZLN e dos movimentos populares, eles vão tentando (re)inventar métodos, encontrar caminhos e aprender. Deste modo, as idéias revolucionárias e transformadoras não ficam circunspectas ao espectro do EZLN, mas também são geradas no seio dos movimentos sociais populares. Em uma visão de longo prazo, e analisando erros de experiências revolucionárias passadas, o EZLN procura a autodissolução e tenta não cair na tentação militarista. Dessa forma, entendem que não basta "derrotar" o inimigo, o importante é construir algo novo, novas relações entre os homens.

Para Sergio Tischeler os novos movimentos sociais - sobretudo o EZLN - adotam um conceito de revolução que abandona a perspectiva do Estado, de uma vanguarda e do poder, o que acaba por conferir um caráter mais radical a esses movimentos, que não reproduzem uma dominação. Trata-se de um conceito mais aberto de revolução que tem por categoria a liberdade; esses movimentos, através da auto-organização e auto-determinação dos sujeitos sociais, e tendo como experiência histórica os soviets russos, lutam contra toda forma de dominação e opressão, pela aniquilação da classe e não sua afirmação, pela criação de um novo sujeito revolucionário,

En ese sentido, se puede afirmar que la lucha de clases no tiene como horizonte el cambio del dominio de una clase por otra, sino el fin de la dominación y de la clase como forma de existencia del poder [...] La revolución ya no es vista a partir de la categoría de poder, sino de la constante lucha del sujeto social contra el poder, contra sus distintas formas, entre ellas las de la política como cultura de la reificación (TISCHELER, 2004, p. 80-84)

É certo que houve uma limitação nos movimentos sociais clássicos da América Latina - e mesmo no mundo -, com as radicais mudanças econômicas, sociais, políticas e ideológicas do último quarto do século XX. O que resultou para Theotonio dos Santos (2004) na adoção, por parte do movimento operário nas décadas de 1970 e 1980, de formas mais cautelosas de atuação, expressas na defesa dos direitos humanos, no restabelecimento da democracia etc. E os "novos movimentos sociais" parecem assumir em suas lutas formas liberais, como a defesa ao voto, políticas de identidade, garantia de direitos iguais de gênero, a questão étnica como componente substancial da cultura nacional etc. Contudo, segundo o autor, estas reivindicações ganharam outra dimensão com o tempo, fazem parte de um projeto político cultural que requer o rompimento com a estrutura econômico-social que 
produz o machismo ${ }^{14}$, o racismo e o autoritarismo, formas que estão substancialmente, enquanto fenômeno histórico, identificadas com o modo de produção capitalista e também,

Asimismo se cuestiona la pretensión de una racionalidad iluminada que tendría como cuna a occidente y que justificaría el colonialismo despreciando sustancialmente la importancia de culturas y civilizaciones del oriente o de las comunidades indígenas precolombinas. Los movimientos sociales comienzan así a romper con la ideología de la modernidad como forma superior y única de civilización. (SANTOS, 2004, p. 73).

Indubitavelmente, na sociedade contemporânea há uma multiplicidade de relações e diversidades, e os movimentos sociais que se pautam por essa perspectiva direcionam suas lutas a outros objetivos - como relacionados à raça, gênero, etnicidade, sexualidade etc. -, com vistas a suprir uma lacuna e uma dívida teórica e prática da esquerda tradicional, ao construir uma política de identidade baseada na diversidade e na diferença, iluminando uma pluralidade de formas de opressão e dominação.

Entretanto, por mais que estas formas de luta se constituam como um imperativo para a construção de uma sociedade mais justa e mesmo para a emancipação humana, não podemos perder de perspectiva a questão da desigualdade de classes como um dos pilares básicos da exploração, opressão e reprodução do sistema capitalista. Neste sentido, o enfoque na existência das "classes" se faz primordial, pois essas se constituem por princípio como uma relação social de exploração, dominação, desigualdade e poder substancialmente diferente das desigualdades sexuais, étnicas e culturais - não esquecendo seu peso e não as relegando a um segundo plano. A problemática se coloca porque, de uma forma geral, as lutas de identidade não significam, necessariamente, o fim do sistema capitalista - e de suas mazelas -, pois, essas lutas podem ser cooptadas, assimiladas e adaptadas aos interesses do capital, ao contrário da luta de classes. Assim, sem o fim da diferenciação de classes, se recolocaria a força da lógica sistêmica e totalizadora do capitalismo, reproduzindo a submissão a esse sistema social ontologicamente desigual.

\footnotetext{
${ }^{14}$ A luta dos zapatistas, além de uma luta maior contra o capital, pela democratização do México ou contra os latifúndios, ao colocar como norte novas formas de se fazer política, novas formas e relações de poder, acaba por desenvolver novas formas de organização e relações dentro de suas fileiras do exército, que se expandem para as próprias comunidades indígenas. Desta maneira, nessas comunidades em que o papel da mulher era reduzido ao de ter filhos e trabalhar (tanto em casa como no campo, e saliente-se que nem o direito de escolher seu marido ela possuía), com a luta pela democracia de uma forma mais ampla, colocou-se também uma luta pelos direitos das mulheres, tanto no EZLN em que ocupam cargos de comando, como significou também uma luta por direitos em suas próprias casas e comunidades.
} 
Não podemos esquecer que o capitalismo

[...] é um processo totalizador cruel que dá forma a nossa vida em todos os aspectos imagináveis, e em toda parte [...] ele submete toda vida social às exigências abstratas do mercado, por meio da mercantilização da vida em todos os seus aspectos, determinando a alocação de trabalho, lazer, recursos, padrões de produção, de consumo, e a organização do tempo. E assim se tornam ridículas todas as nossas aspirações à autonomia, à liberdade de escolha e ao autogoverno democrático (WOOD, 2003, p. 224).

É necessário que se coloque a urgência da superação radical desse modo de produção e organização social. Não se pode combater o capitalismo apenas de modo aparente, em pequenos aspectos que podem ser assimilados por ele, isso significaria uma busca enganosa por liberdade e justiça em um mundo em que não existe nem uma coisa e nem outra. A modificação da sociedade tem que englobar todos os aspectos da reconstrução da vida social, através de uma crítica radical a tudo o que fundamenta essa sociedade (o mundo da reificação, da ideologia, do Estado e suas separações, do trabalhador-mercadoria, da hierarquia e burocracia, da dicotomia público X privado, indivíduo X sociedade, do racismo, das questões de gênero, étnicas etc.). A revolta contra esse sistema capitalista se situa no plano da totalidade, porque seja nos confins do México, nas ruas da Argentina ou da Bolívia, ela é uma revolta do ser humano contra sua própria existência desumana, um lampejo de vida contra a escuridão que a "morada de ferro do capitalismo" nos têm aprisionado, que nega nossa possibilidade mesmo de vida em troca de uma lógica da sobrevivência cada vez mais difícil e seletiva.

Parece-nos que uma das grandes forças do zapatismo reside precisamente no fato deles conseguirem compreender que seus interesses não são distintos dos interesses de todos os que sofrem a exploração e opressão generalizada desse sistema social, e que, portanto, o problema não se encontra apenas - ele também se encontra, mas não tão somente -, no estatuto dos indígenas no Estado capitalista ocidental, mas no próprio Estado capitalista ocidental, que é criticado hoje pelos indígenas na América Latina ${ }^{15}$.

Contudo, como coloca Emir Sader (2004), a luta zapatista conseguiu consolidar seu poder local - com os caracóis e as juntas de bom governo -, fortalecendo sua capacidade de ação local e seu apoio no estado de Chiapas, em sua luta por reconhecimento dos direitos, da identidade e autogoverno das

$15 \mathrm{O}$ discurso indianista contemporâneo é fruto das pressões que a globalização neoliberal tem realizado sobre suas próprias condições de sobrevivência. A revitalização identidária aparece assim como um meio de resistência e não é casual que a construção étnica emerja de uma conflitualidade social de forte caráter anti-neoliberal e de seus ajustes estruturais, não obstante junto com os elementos de especificidade de cada região. (ZALDíVAR, 2005). 
comunidades chiapanecas. Entretanto, ele percebe uma diminuição das tentativas do EZLN em apresentar-se (direta ou indiretamente) como uma alternativa nacional, neste sentido, a vida política mexicana estaria a girar em torno dos partidos tradicionais. Isto, em certo sentido, em decorrência do EZLN renunciar a propor um modelo hegemônico alternativo em escala nacional ao neoliberalismo.

\begin{abstract}
A teorização da transformação do mundo 'sem tomar o poder', influencia diretamente esta opção dos zapatistas. A crítica dos partidos tradicionais e do próprio Estado, tendeu para a supervalorização tanto dos movimentos sociais, quanto da ação de base, em detrimento da luta política e da busca de construção de uma hegemonia alternativa. O abismo entre os zapatistas e o PRD [tradicional partido social-democrata], por exemplo, se manteve e assim os planos social - neste caso, campesino e indígena - e político nacional (SADER, 2004, p.59-60).
\end{abstract}

\title{
E complementa Emir Sader, afirmando que
}

A crítica dos partidos existentes ou mesmo da forma partido não abole a questão do poder e da hegemonia, não abole a política. A força dos movimentos sociais, por si só, pode no máximo construir poderes locais - importantes, mas limitados, especialmente na época de hegemonia imperial - ou exercer o poder de veto. Tratase por tanto de ocupar esse espaço de outra forma, com formas distintas de fazer política, mas trabalhando na perspectiva da construção de uma hegemonia alternativa, que representa à grande maioria da população, expropriada pelo neoliberalismo dos seus direitos essenciais (SADER, 2004, p. 64).

Realmente, se fazem necessárias alternativas - práticas e teóricas -, que se coloquem em confronto com a perspectiva hegemônica liberal, entretanto, que não caia em um relativismo absoluto que apenas reforça essa ordem social. Alternativas que estão sendo criadas - ao menos em parte -, no cotidiano de resistência dos municípios autônomos em rebeldia de Chiapas, mas e não apenas lá.

São diversas hoje as indagações acerca do que fazer, de qual caminho seguir, se existe realmente uma alternativa. A nova ordem mundial trouxe consigo um imperativo de novas formas de se pensar a organização social e também tarefas novas, não apenas para a esquerda, mas também para a direita. As lutas autônomas que são travadas cotidianamente acabam por se inserir de uma ou outra forma no sistema capitalista, seja por cooptação, seja pela assimilação através do mercado ou por impossibilidade de sozinhas seguirem adiante. Ainda assim há um grito de revolta, e para além do grito, lutas reais que estão sendo travadas. Se o capitalismo vai ter ou não capacidade de absorção dessas lutas esse é um outro ponto, de qualquer forma elas 
começam a deixar os germes de novas propostas, novas relações, novos saberes e, talvez, sejam os primeiros passos, ou melhor, se somem com os passos de rebeldias e resistências passadas, para se fundar a radical superação da sociabilidade regida pelo capital.

\section{REFERÊNCIAS}

ARELlanO, A. B.; OlIVEIRA, A. U. (Org.). Chiapas: construindo a esperança. São Paulo: Paz e Terra, 2002.

BRIGE, M.; DI FELICE, M. Votán-Zapata: a marcha indígena e a sublevação temporária. São Paulo: Xamã, 2002.

BORON, A. Filosofia politica marxista. São Paulo: Cortez, 2003.

CECEÑA, A. E. Pela humanidade e contra o neoliberalismo: linhas centrais do discurso zapatista. In: SEONE, J.; TADDEI, E. Resistências mundiais: de Seattle a Porto Alegre. Rio de Janeiro: Vozes, 2001. p.186-199.

CHASIN, J. A sucessão na crise e a crise na esquerda. Ensaio, São Paulo, n. 17-18, p. 120, 1989.

CRESPO, Regina Aída. Chiapas: O movimento indígena armado no panorama político e econômico do México. Terra Indígena, ano 13, n. 80, p. 31-45, 1996. Número especial. DÁVALOS, Pablo. Movilización indigena, autonomia y plurinacionalidad. Texto do Curso Clacso - Pueblos indígenas, globalización y Estado plurinacional, 2005a. Disponível em: <www.clacso.edu.ar>. Acesso em: jan. 2006.

. El Discurso del Desarrollo y la Identidad: Discusión conceptual-epistemológica. Texto do Curso CLACSO - Pueblos indígenas, globalización y Estado plurinacional, 2005b. Disponível em: <www.clacso.edu.ar>. Acesso em: jan. 2006.

FIGUEIREDO, Guilherme Gitahy de. A guerra é o espetáculo: origens e transformações da estratégia do EZLN. 2003. Dissertação (Mestrado) - IFCH, Unicamp, Campinas, 2003. GENNARI, Emílio. Chiapas: as comunidades zapatistas reescrevem a história. Disponível em: 〈http://www.chiapas.hpg.ig.com.br/alternat00_1.html>. Acessado em: 19 out. 2001. GÓMEZ, Magdalena. El derecho indígena, conceptos básicos y sus retos. Texto do Curso Clacso - Pueblos indígenas, globalización y Estado plurinacional, 2005. Disponível em: <www.clacso.edu.ar>. Acesso em: jan. 2006.

. Pueblos indígenas en América Latina: entre el Estado y la Nación. Anuario social e politico de América Latina y el Caribe, Caracas, n. 5, p. 57-59. 2002.

HILSENBECK FILHO, A.M. O zapatismo e o fim da história. Revista de Iniciação científica da Faculdade de Filosofia e Ciências, Marilia, v. 4, n. 3, 2004. Disponível em <http:// revistas.marilia.unesp.br/viewarticle.php?id=47\&lay out=abstract $>$. Acesso em: 19 maio 2005.

. O EZLN e a guerrilha informacional: a política no mundo encantado da mídia e da comunicação. In: CONGRESSO VIRTUAL DE ARQUEOLOGIA E ANTROPOLOGIA, 4., 2004, Marilia. Disponível em: <http://www.naya.org.ar/ congreso2004/ ponencias/alexander_maximilian.doc. Acesso em: 19 maio 2005.

HOLLOWAY, J. O zapatismo e as ciências sociais na América Latina. Revista Novos Rumos, São Paulo, ano 17, n. 36, p. 4-10, 2002.

LE BOT, Yvon. O sonho zapatista. Lisboa: Asa, 1997. 
LENIN. V. I. Obras completas. São Paulo: Abril, 1985.

LOUREIRO, Isabel. Rosa Luxemburg: Os dilemas da ação revolucionária. São Paulo: Unesp, 1995.

LUXEMBURGO, Rosa. Reforma social ou revolução? São Paulo: Global, 1986.

MARCOS, Subcomandante. Chiapas: o sudeste entre dois ventos, uma tempestade e uma profecia, 1992. Disponível em: <http://www.chiapas.hpg.ig.com.br/1994.html〉. Acesso em: 19 maio 2002.

ORNELAS, Raúl. LA autonomia como eje de la resistencia zapatista: del levantamiento armado al nacimiento de los Caracoles. In.: CECEÑA. A. E. (Org.) Hegemonias y emancipaciones en el siglo XXI. Buenos Aires: CLACSO, 2004. p. 133-172.

PETRAS, J.; VIEUX, S. Mitos e realidades da sublevação de Chiapas. Lutas sociais, São Paulo, n. 5, 1998.

PINEDA, Francisco. La guerra de baja intensidad. Revista Chiapas, n. 2. 1996. Disponível em:<http://www.ezln.org/revistachiapas>. Acesso em: 7 mar. 2003.

SADER, Emir. Reflexões sobre a luta antineoliberal. OSAL, Buenos Aires, n. 15, p. 57 64, 2004.

SAINT-PIERRE, Héctor Luís. O paramilitarismo como vetor da guerra de contrainsurgência. Crítica marxista, São Paulo, n. 9, p. 110-123, 1999.

SANTOS, Theotonio dos. De la resistência a la ofensiva: el programa alternativo de los movimientos sociales. OSAL, Buenos Aires, n. 15, p. 65-76, 2004.

SIMBAÑA, Floresmilo. Textos do Curso Clacso - Pueblos indígenas, globalización y Estado plurinacional, 2005. Disponível em: 〈www.clacso.edu.ar〉. Acesso em: jan. 2006.

TISCHLER, Sergio. La forma clase y los movimientos sociales en América Latina. OSAL, Buenos Aires, n. 13, p. 77-85, 2004.

TONET, Ivo. Democracia ou liberdade? Maceió: UFAL, 1997.

WOOD, E. M. Democracia contra capitalismo: a renovação do materialismo histórico. São Paulo: Boitempo, 2003.

ZALDÍVAR, V. B. S. Capital social, etnicidad y desarrollo: algunas consideraciones críticas desde los andes ecuatorianos. Texto do Curso Clacso - Pueblos indígenas, globalización y Estado plurinacional, 2005. Disponível em: 〈www.clacso.edu.ar〉. Acesso em: jan. 2006. 
